\section{Performance of intumescent coatings in cone calorimeter and open pool fires}

\author{
Saket Singh, ${ }^{1}$ Sumit Shivani, ${ }^{1}$ \\ Sudheer Siddapureddy, \\ Siddini Venkatesh Prabhu ${ }^{1}$ \\ ${ }^{1}$ Department of Mechanical \\ Engineering, Indian Institute of \\ Technology, Bombay; ${ }^{2}$ Department of \\ Mechanical Engineering, Indian \\ Institute of Technology, Dharwad, India
}

\begin{abstract}
Accidental fire is a major concern in terms of safety of infrastructures and human lives. With the technological advancement, several novel methods are developed for minimizing the damages caused by the fire. One of the methods is to paint the base metals/material with fire retardant coatings which can increase the lead time so that economic destruction and loss of human lives can be avoided. In this work, the performance of the intumescent coating (passive type fire retardant coatings) is studied with the help of cone calorimeter and open pool diesel fire as sources of heat. The transient temperature distribution for bare Stainless Steel 310 plate suggests that the cone calorimeter experiments alone cannot suffice for mimicking real life conditions. Comparison of the behavior of the available paints in cone calorimeter and open pool fire confirms that the performance of intumescent coatings in cone calorimeter is very different from that in open pool fire. The safe initial thickness of the intumescent coating is a function of heat release rate of the source. The effective thermal conductivity of the intumescent coatings is evaluated using one dimensional conduction heat equation with constant boundary temperature condition.
\end{abstract}

\section{Introduction}

Metals play a very important role in providing strength to different types of structures. They are the back bone of any kind of construction. Structures like buildings, warships, etc. uses heavy amount of steel and aluminum parts for good strength on a long run of life. But accidents like what happened in New York (11/09), wars damages the metallic support used in construction, due to exposure of very high temperature. Such kinds of situations are very likely to happen in naval warships. To avoid either those kind of destruction or to get a lead time to evacuate lives, the structures need to be protected. The protection of the structures can be ensured using fire resistant coatings. The use of intumescent coating is one of the most preferred ways to protect substrate from fire. ${ }^{1,2}$ The interesting property of an intumescent paint is that it does not affect the thermo-physical or any other property of the substrate. It can be easily applied on to the surface with the help of brush, spray or roller and this paint can be used on any type of solid material like flax boards, ${ }^{3}$ textiles ${ }^{4}$ and metals. ${ }^{5}$

Intumescent paint as the name suggests intumesces when the surface temperature reaches the pyrolysis temperature. There are several theories published in the literature on the mechanism of working of intumescent paints. Deogan et al. ${ }^{6}$ proposed a one dimensional behavior of the intumescent paint to protect the substrate from fire. When heat is applied to a surface coated with an intumescent paint, it was assumed that no reaction occurred until a critical temperature was reached. Subsequently, an infinitesimally thin front, at which the intumescence occurs, moves through the layer of paint. The temperature at this front is firmly clamped at critical temperature but behind the front (i.e. in the portion where the front has passed) the temperature will rise and ahead of the front (i.e. between the substrate and the front) the temperature must be less than the critical temperature.

Jimenez et al. ${ }^{7}$ and $\mathrm{Gu}$ et al. ${ }^{8}$ observed that, an intumescent paint is a combination of three compounds; an acid source, a carbon source and a blowing agent. The moment temperature of the surface reaches the critical temperature of the compound, acid source breaks down to yield a mineral acid, then it takes part in dehydration of the carbonization agent to yield the carbon char, and finally the blowing agent decomposes to yield gaseous products, this causes the char to swell in porous form and thus provides the insulation protective layer. The quantity of the three compounds should be selected intelligently based on a set of experiments so that a physical and chemical balance is maintained. Otherwise proper intumescent behavior may not happen.

Due to the wide range of applications and advantages of using intumescent paints as fire retardant coatings, there is substantial research on intumescent coatings, especially, involving the composition. Recently, nanocoating based intumescent coatings are now available. ${ }^{9}$ Literature exists on the methods for testing intumescent paints, using cone calorimeter, ${ }^{10,11}$ premixed flame $^{12}$ and even solar furnace. ${ }^{13}$ The comparison of the intumescent paints is carried out mainly based on their behavior under different heat fluxes using cone calorimeter.

Large amount of research work is
Correspondence: Sudheer Siddapureddy, Department of Mechanical Engineering, Indian Institute of Technology, Dharwad, 580011, India.

Tel.: +91.8362212847

E-mail: sudheer@iitdh.ac.in

Key words: Intumescent coatings; Open pool fires; Thermal conductivity.

Contributions: S. Singh contributed in performing all the experiments, collecting the data, analyzing the data; S. Shivani contributed in analyzing the data; $\mathrm{S}$. Siddapureddy contributed in performing cone calorimeter experiments and open pool fire experiments; SVP contributed in the conception of the idea.

Conflict of interest: the authors declare no potential conflict of interest.

Funding: none.

Received for publication: 17 October 2017

Revision received: 22 February 2019.

Accepted for publication: 8 April 2019.

This work is licensed under a Creative Commons Attribution 4.0 License (by-nc 4.0).

(C) Copyright S. Singh et al., 2019

Licensee PAGEPress, Italy

Fire Research 2019; 3:45

doi:10.4081/fire.2019.45

reported on the modeling of the intumescent coatings behavior. Mesquita et al. ${ }^{14}$ considered intumesced char as a solid body and assumed one-dimensional conduction to determine the thermal conductivity of the char as a function of time and also used inverse heat conduction methodology to improve the thermal conductivity prediction. Staggs ${ }^{15}$ shows that direct numerical simulation can also be used to estimate the thermal conductivity of the intumesced char. Zeverov et al. ${ }^{11}$ determines the thermo-physical property of the intumescent Paint as a function of temperature and has given a set of equations to predict the substrate's behavior under premixed flame. Staggs et al. ${ }^{16}$ demonstrates the use of three dimensional thermal resistor networks to calculate the thermal conductivity and then compares with the analytical and experimental estimates of $\mathrm{Al}_{2} \mathrm{O}_{3}$.

Published research work on intumescent coatings is either performed in a closed furnace using ISO 864 curve's temperature or with the help of cone calorimeter which have the capability of providing constant heat flux. But, accidental fires that occur in an open area like warships or any other structure that is exposed to hydrocarbon pool fires pose much harsher environment 
to the intumescent coatings. Hence, there is a need to study the intumescent coatings in open pool fires. The present work concentrates on the behavior of the intumescent paints under different heat release rates using $0.5 \mathrm{~m}$ and $0.7 \mathrm{~m}$ open pool diesel fire. The present work demonstrates that the conclusions drawn on the basis of cone calorimeter experiments are not sufficient for real life application purpose. The paints need to be tested in real fire conditions. Temperature reduction ratio is used to determine the safe thickness for a given heat release rate of the heating source. The thermal conductivity of the paint is also calculated using the methodology given by Qiang et al. ${ }^{17}$ and the fire temperature distributions given by Sudheer and Prabhu. ${ }^{18}$

\section{Materials and Methods}

Experimental set-up and procedure

Mass loss cone calorimeter (FTT make) is used as the controlled heat flux source as shown in Appendix Figure 1. It consists of the heating coil at the top, a sample holder and a load cell. The calibration of the heating coil is carried out with the help of a heat flux sensor (Schmidt-Boelter Heat Flux Sensor) at a distance of $60 \mathrm{~mm}$ from the bottom of the heating coil. Therefore, target plates are placed on a standard sample holder of the cone calorimeter above the ceramic blanket. Ceramic blanket of $25 \mathrm{~cm}$ thickness is filled in between the back side of the plate and the holder to avoid the heat loss from the back of the plate.

Appendix Figure 2 shows the schematic of the experimental set-up. Circular containers of 0.5 and $0.7 \mathrm{~m}$ made of mild steel are used for conducting open pool fire experiments. The containers are filled with 10-12 and 20-25 liters of diesel, respectively. Fire is initiated by pouring $10-20 \mathrm{ml}$ of gasoline which acts as an igniter. Experiments are performed in the early hours of the day ( $5 \mathrm{pm}-7 \mathrm{pm})$ so that the wind velocity is minimal. The experiments are conducted until steady state temperatures of the plate are achieved. The location of the coated Stainless Steel 310 plate is at $Y / D=0.22$ from the fuel surface and at $X / D=0.13$ as shown in Appendix Figure 2 . Three thermocouples (k-type) are welded on the back side of the Stainless Steel 310 plate.

Experiments are conducted on the bare Stainless Steel 310 plates $(d=2 \mathrm{~mm}, 4 \mathrm{~mm}$ and $6 \mathrm{~mm}$ thickness) of $100 \mathrm{~mm} \times 100 \mathrm{~mm}$ in cone calorimeter $\left(50 \mathrm{~kW} / \mathrm{m}^{2}\right)$ and $0.5 \mathrm{~m}$ open pool diesel fire.

Performance of the paint A (Goa paints) and paint $\mathrm{B}$ (Nu-kem paints) is evaluated in both cone calorimeter and $0.5 \mathrm{~m}$ open pool diesel fire. It should be noted that the Paint A has weak adhesive property compared to Paint B. For cone calorimeter experiments, a Stainless Steel $310(2 \mathrm{~mm})$ is coated with a dry film thickness (dft) of $1.5 \mathrm{~mm}$ and 2.5 $\mathrm{mm}$. Experiments are conducted at a heat flux of $50 \mathrm{~kW} / \mathrm{m}^{2}$. Intumescence rate is captured using thermal infra-red camera (Thermoteknix VisIR 320-P) and digital camera (Canon PowerShot SX110 IS). For

SS 310 bare plate $(\delta=2 \mathrm{~mm})$
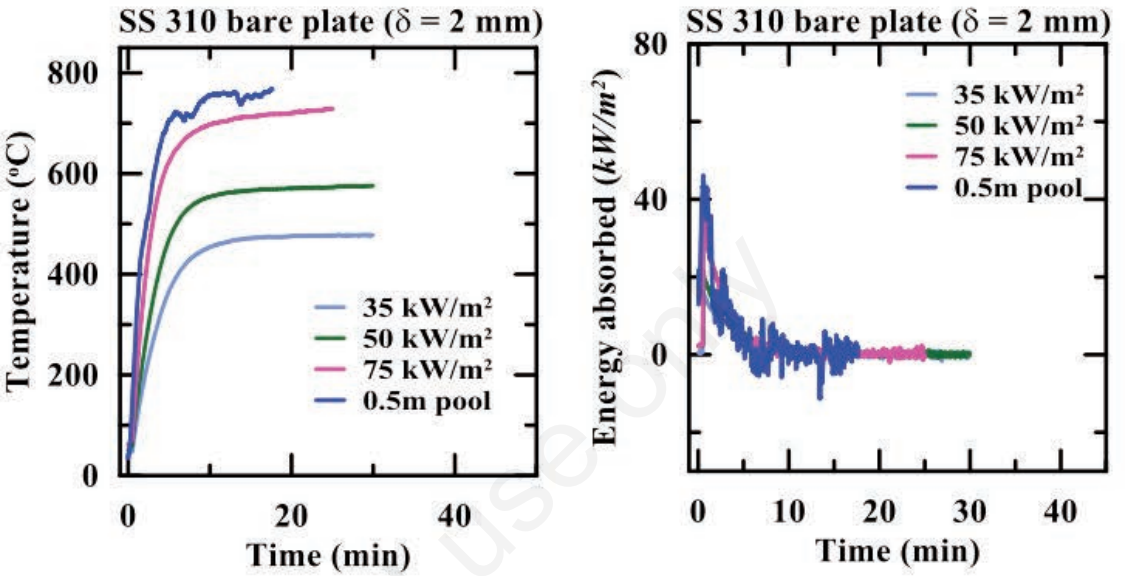

SS 310 bare plate $(\delta=4 \mathrm{~mm})$
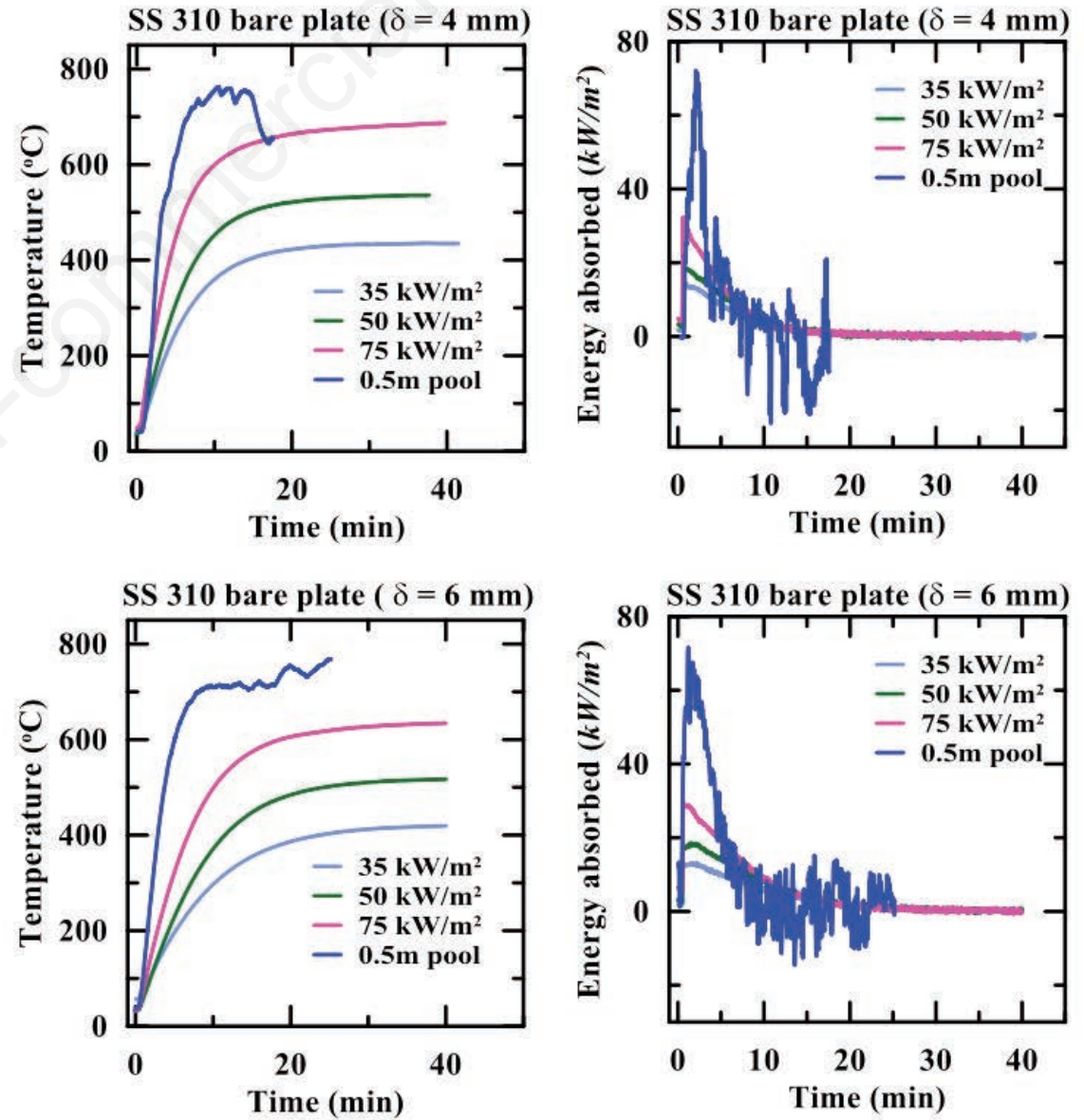

$0.5 \mathrm{~m}$ open pool fire experiments, three thicknesses of Stainless Steel 310 plates (2 $\mathrm{mm}, 4 \mathrm{~mm}$ and $6 \mathrm{~mm}$ ) are coated with dry film thickness of $0.5 \mathrm{~mm}, 1.5 \mathrm{~mm}, 2.5 \mathrm{~mm}$ and $3.5 \mathrm{~mm}$ of paint $\mathrm{A}$ and paint $\mathrm{B}$. The optimum thickness of paint $\mathrm{B}$ for a given heat release rate of heating source is arrived by conducting experiments both in 0.5 and $0.7 \mathrm{~m}$ open pool diesel fire.

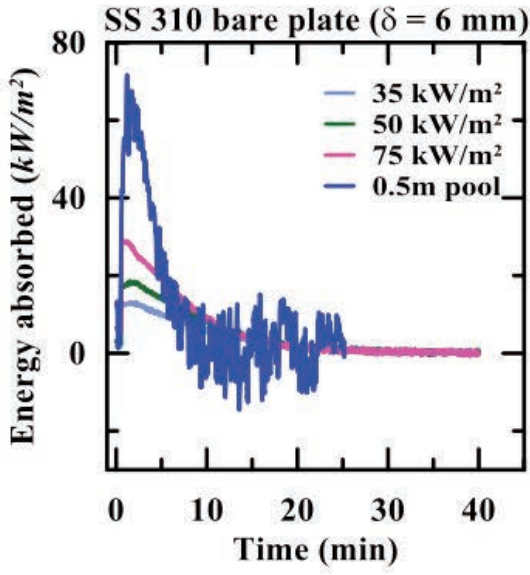

Figure 1. Temperature and energy absorbed by Stainless Steel 310 plates exposed in cone calorimeter and $0.5 \mathrm{~m}$ pool fire. SS310, stainless steel 310 . 


\section{Results and Discussion}

\section{Behavior of bare plate in cone} calorimeter and open pool fire

Experiments are performed for different plate thicknesses $(2 \mathrm{~mm}, 4 \mathrm{~mm}$ and $6 \mathrm{~mm})$ with varying heat fluxes $\left(35 \mathrm{~kW} / \mathrm{m}^{2}, 50\right.$ $\mathrm{kW} / \mathrm{m}^{2}$ and $75 \mathrm{~kW} / \mathrm{m}^{2}$ ) in cone calorimeter and also in open pool diesel fire. At any given instant, the temperature measured by three thermocouples are averaged and shown in Figure 1. Energy absorbed by the plate contributes to the rise in temperature of the plate. This is calculated using the heat equation shown below:

$$
\text { Energy absorbed by the plate }=\left(\rho V C_{p}\right)_{s} \frac{d T}{d t}
$$

Variation of temperature and energy absorbed by the plates with time (for $2 \mathrm{~mm}$, $4 \mathrm{~mm}$ and $6 \mathrm{~mm}$ ) are shown in Figure 1. Temperature of the plate for pool fire keeps on fluctuating after reaching the maximum temperature. This is usually because of the wind which disturbs the steadiness of the fire/flame. The steady state temperature of the plates is around $770^{\circ} \mathrm{C}$ irrespective of the thickness of the plate in an open pool fire environment. However, the steady state temperatures are different for different thickness in cone calorimeter for a given heat flux ( $d=2,4$ and $6 \mathrm{~mm}$ ). The temperature distribution suggests that the fire environment poses more severity on the bare plate compared to the cone calorimeter even at higher heat flux of $75 \mathrm{~kW} / \mathrm{m}^{2}$. Hence, it may be concluded that the results inferred from cone calorimeter may not be valid for open pool fire environment. It should be noted that the pool fire experiment didn't last 20 minutes longer in case of $d=4 \mathrm{~mm}$ and thus there is dip in the temperature.

\section{Comparison of paint $A$ and paint $B$ in cone calorimeter}

Influence of dry film thickness $(1.5 \mathrm{~mm}$ and $2.5 \mathrm{~mm}$ ) on the temperature, energy absorbed, mass loss rate and intumescent height of a stainless steel plate exposed to $50 \mathrm{~kW} / \mathrm{m}^{2}$ in a cone calorimeter is studied. Two paints considered in this study are paint $\mathrm{A}$ and paint $\mathrm{B}$.

Figure 2 and Appendix Figure 3 show the transient temperature distribution of the stainless steel plate coated with a dry film thickness of $1.5 \mathrm{~mm}$ and $2.5 \mathrm{~mm}$ respectively. The performance of paint A and paint B appears to be almost same in terms of energy absorbed. However, from thermal shielding perspective, paint A shields slightly better in terms of temperature variation of the steel plate in comparison with paint B.

Figure 3 shows the mass loss fraction (mass of the paint at any instant/initial mass of the paint) of the intumescent paints. The mass loss fraction for the paint $\mathrm{B}$ is higher as compared to the paint $\mathrm{A}$ for both dry film thickness (1.5 $\mathrm{mm}$ and $2.5 \mathrm{~mm})$. This shows that the initial thermal shielding contribution by the paint $\mathrm{B}$ may be more due to the evolution of the gases as compared to the paint $\mathrm{A}$. However, in paint $\mathrm{A}$, the contribution of gaseous evolution towards the cooling effect may be less predominant.

Appendix Figure 4 shows the intumescent thickness development for the paint $\mathrm{A}$ and B with an initial dry film thickness of $1.5 \mathrm{~mm}$ and $2.5 \mathrm{~mm}$. The final intumescent height for the paint B is higher compared to that of paint A. One of the probable reasons for higher intumescence is the total volume of gaseous evolution. Porosity is directly proportional to the gases evolved during the decomposition. Although, the porosity and solid fraction of both the intumesced char is different, the effective thermal conductivity is close enough that intumesced char allows almost same heat transfer through it.

\section{Comparison of paint $A$ and paint $B$ in a $0.5 \mathrm{~m}$ open pool diesel fire}

In the previous section, comparison of paints in cone calorimeter environment is

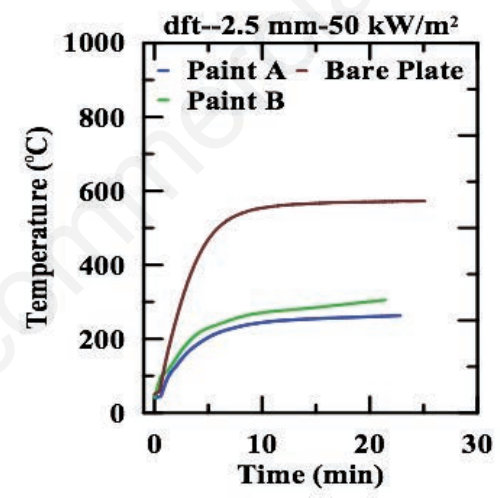

Figure 2. Variation of temperature and energy absorbed by Stainless Steel 310 plates for a dry film thickness of $\mathbf{2 . 5} \mathbf{m m}$. dft, dry film thickness.
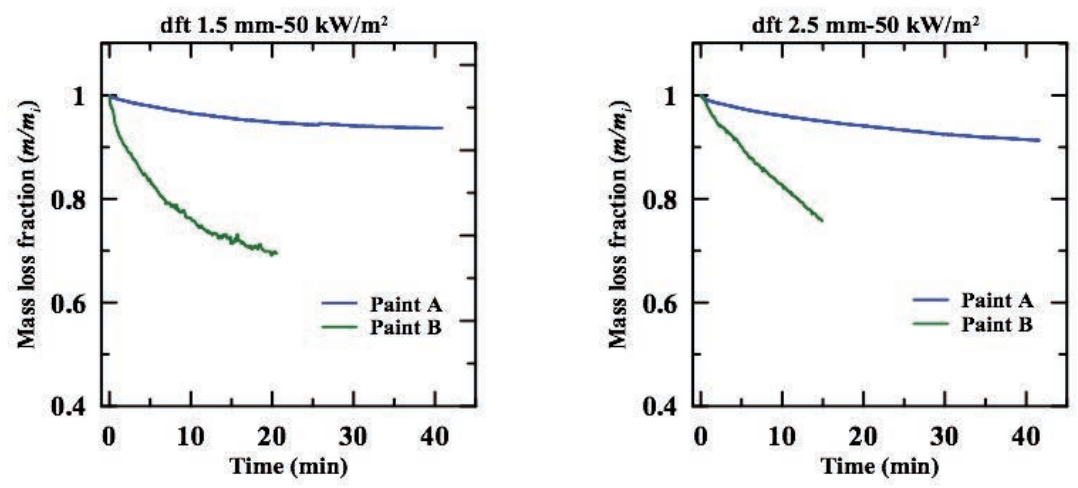

Figure 3. Comparison of mass loss fraction for different paints. dft, dry film thickness.

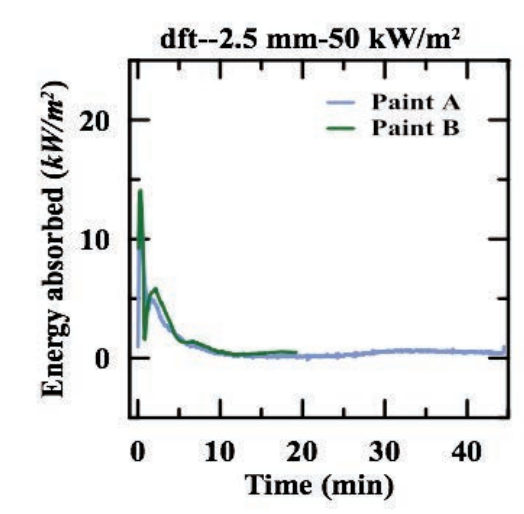

studied. Cone calorimeter is often preferred because of clean heating environment and a good control on the heat flux. Several differences between the environment in fire and cone calorimeter are as follows: i) varying heat flux with time in an open pool fire as opposed to constant heat flux in cone calorimeter; ii) sooty flame environment in pool fire compared to clean heating in cone calorimeter; iii) forced convective environment exists in pool fire (greater than $0.3 \mathrm{~m}$ pool fire) as opposed to natural convective environment in cone calorimeter. It may be concluded that the open pool fire environment is more hostile than the cone calorimeters (Figure 1). Hence, choosing a better paint is to be accomplished on the basis of pool fire experiments rather than cone calorimeter experiments.

Figure 4 shows the live image of the experiment with $0.5 \mathrm{~m}$ open pool diesel fire. The image clearly shows the unsteady nature of the open pool fire. Due to the unsteady behavior of the flame, experiments are repeated more than twice and are averaged to get the final readings. Variations of temperature along with the energy absorbed by the Stainless Steel 310 plates $(2 \mathrm{~mm})$ with time (for different dry film thicknesses of the two paints) are 
shown in the Appendix Figure 5.

Paint A performs similar to paint B for a dry film thickness of 0.5 and $1.5 \mathrm{~mm}$. But with dry film thickness greater than 1.5 $\mathrm{mm}$, the temperature profile of the plate is less predictable for Paint A. This is because the intumesced char formed by paint $A$ falls off during the course of the experiment. The temperature distribution and the energy absorbed by paint B follow a smooth curve for different plate thickness and dry film thicknesses. For initial 4-8 minutes, the variation of the temperature for both the paints is same. But with the progression of time, paint A suddenly deviates from the smooth behavior. The reason behind this sudden change in the nature of the curve is the falling off of the swelled char from the plate leaving the plate unprotected. The peeling of the swelled char from the metal plate results in the disturbed energy absorption profile of the plate. Therefore, although the insulation property of paint A is good, due to its weak adhesive property, paint $A$ fails in protecting the metal plate from high temperature exposure. On the other hand, the temperature profile and the energy absorbed distribution for Paint B follows a smooth behavior for Stainless Steel 310 plate thicknesses $(2 \mathrm{~mm}, 4 \mathrm{~mm}$ and $6 \mathrm{~mm})$ and different dry film thicknesses. The energy absorption rate is high for initial 1-2 minutes. However, with the passage of time, energy absorption rate decreases. This is because of the formation of the porous char due to high heat flux exposure. The adhesive strength of paint B upon swelling is better than Paint A.

\section{Optimum thickness of paint $B$ for 0.5 and $0.7 \mathrm{~m}$ diameter open pool diesel fire}

The heat release rate for $0.5 \mathrm{~m}$ and 0.7 $\mathrm{m}$ open pool diesel fire is $0.207 \mathrm{MW}$ and $0.502 \mathrm{MW} .{ }^{18}$ Figure $5 \mathrm{~A}$ shows the condition of stainless steel plate coated with a dry film thickness of $1.5 \mathrm{~mm}$ of paint B. Paint B intumesces gets transformed into highly porous intumesced char in cone calorimeter (as presented in previous section). In cone calorimeter, a $1.5 \mathrm{~mm}$ dry film thickness of paint B expands around 18-20 times of its initial thickness. However, in an open pool fire, a $1.5 \mathrm{~mm}$ dry film thickness of paint $B$ expands to only 10 times of its initial thickness (Figure 5A). Figure 5B shows the front view of the intumesced char on Stainless Steel 310 plate after the exposure to fire. The surface of the intumesced char is covered with soot from the diesel pool fire. This kind of participating behavior of the pool fire may be responsible for lesser intumescent height development. However, exact chemistry is not understood. SS310 plate can withstand a maximum tempera- ture without thermal damage is $700^{\circ} \mathrm{C}$.

Appendix Figure 6A shows the temperature variation for Stainless Steel 310 plates of different thicknesses $(2 \mathrm{~mm}, 4 \mathrm{~mm}$ and 6 $\mathrm{mm})$ coated with 4 different dry film thickness $(0.5 \mathrm{~mm}, 1.5 \mathrm{~mm}, 2.5 \mathrm{~mm}$ and $3.5 \mathrm{~mm})$ of paint $\mathrm{B}$ in $0.5 \mathrm{~m}$ open pool fire. Each experiment is repeated twice. There is improvement in the insulation capacity of the intumescent paint with the increase in dry film thickness, irrespective of the plate thickness. The temperature profiles with dry film thicknesses of $0.5 \mathrm{~mm}$ and $1.5 \mathrm{~mm}$ cross each other. However, there is a monotonic decrease in the temperature profile with the increase in the dry film thickness for thickness greater than or equal to 1.5 $\mathrm{mm}$. There is a monotonic decrease in the energy absorbed by the plate with the increase in the dry film thickness of the paint. The temperature profile for $2.5 \mathrm{~mm}$ dry film thickness of the paint has lower slope compared to $0.5 \mathrm{~mm}$ and $1.5 \mathrm{~mm}$ paint thicknesses. $2.5 \mathrm{~mm}$ dry film thickness can hold the fire for more than $25 \mathrm{~min}$ utes for plate thickness of $2 \mathrm{~mm}$. However,

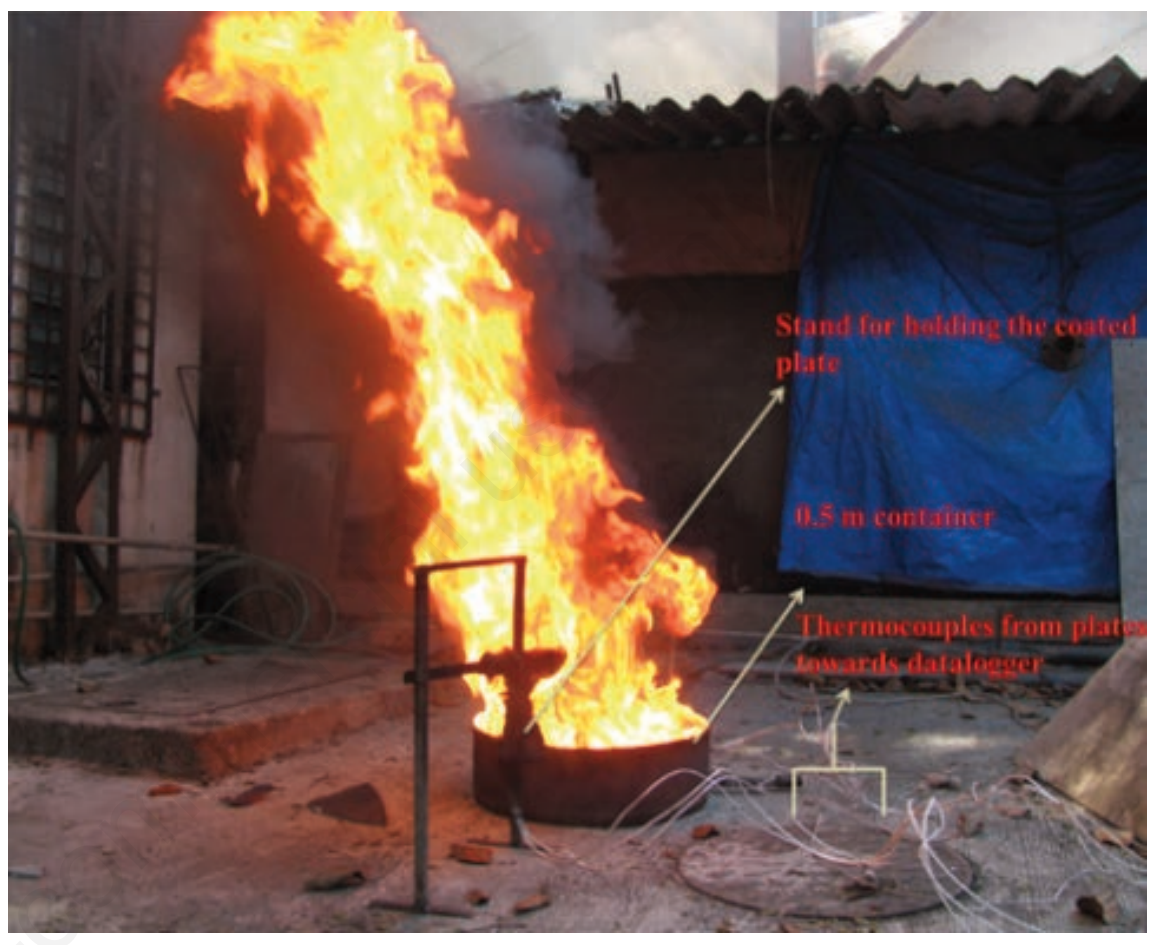

Figure 4. Photograph of the $0.5 \mathrm{~m}$ open pool diesel fire.

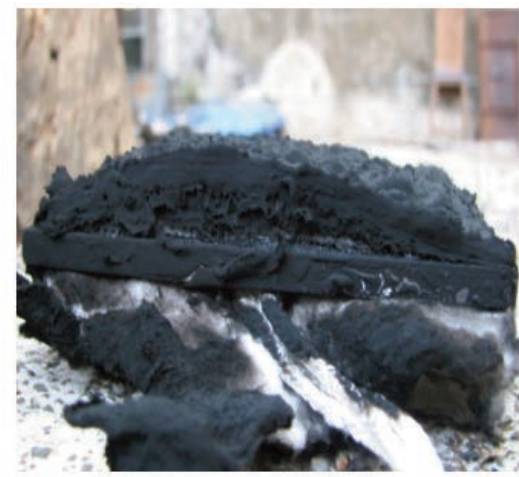

A

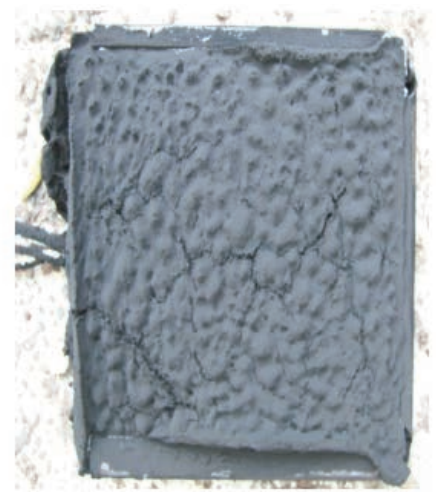

B

Figure 5. Intumesced plate exposed to fire with a dry film thickness of $1.5 \mathrm{~mm}$ for paint B. A) Side view; B) front view. 
after $25 \mathrm{~min}$, the steel temperature reaches the $600^{\circ} \mathrm{C}$ mark. Similar behavior is observed for $4 \mathrm{~mm}$ thick Stainless Steel 310 plate. However, for $6 \mathrm{~mm}$ plate after 18 minutes, the temperature profile for $2.5 \mathrm{~mm}$ dry film thickness merges with temperature profile for $0.5 \mathrm{~mm}$ thickness. On the other hand, $3.5 \mathrm{~mm}$ dry film thickness for $6 \mathrm{~mm}$ plate appears to be better insulating thickness. Hence, maximum temperature attained by a Stainless Steel 310 plate with $3.5 \mathrm{~mm}$ dry film thickness decreases with the increase of Stainless Steel 310 plate thickness. This is because of the thermal inertia of the Stainless Steel 310 plate.

Appendix Figure 6B shows the energy absorption rate for Stainless Steel 310 plates of different thicknesses $(2 \mathrm{~mm}, 4 \mathrm{~mm}$ and $6 \mathrm{~mm}$ ) coated with 4 different dry film thickness $(0.5 \mathrm{~mm}, 1.5 \mathrm{~mm}, 2.5 \mathrm{~mm}$ and 3.5 $\mathrm{mm}$ ) of Paint B in a $0.5 \mathrm{~m}$ open pool fire. The energy absorbed by bare plate is the maximum. Energy absorbed by the SS 310 plate decreases with increase in the dry film thickness of paint B. Figure 6A shows the temperature variation with time and Figure $6 \mathrm{~B}$ shows the energy absorption rate for 0.7 $\mathrm{m}$ open pool fire. The steady state temperature for Stainless Steel 310 bare plates is $827^{\circ} \mathrm{C}$ as against $777^{\circ} \mathrm{C}$ in case of $0.5 \mathrm{~m}$ pool fire. This variation in the steady state temperature is due to the difference in the heat release rates of the two pool fires. The temperature distribution for all the dry film thicknesses of paint B shows the expected behavior for initial 6-8 minutes. The temperature of the Stainless Steel 310 plate decreases with the increase in the dry film thickness of the paint B. Except for $1.5 \mathrm{~mm}$ dry film thickness of paint B, all other dry film thicknesses are showing monotonous behavior for 20 minutes. Thus, from the temperature distributions of Stainless Steel 310 plates in $0.7 \mathrm{~m}$ open pool fire, a $3.5 \mathrm{~mm}$ dry film thickness of paint $B$ is showing better insulation property compared to the other dry film thicknesses. The difference in the slopes of the temperature distribution of Stainless Steel 310 plates for dry film thicknesses $(0.5 \mathrm{~mm}, 1.5 \mathrm{~mm}, 2.5 \mathrm{~mm}$ and 3.5 $\mathrm{mm}$ ) in a $0.5 \mathrm{~m}$ open pool fire is greater compared to $0.7 \mathrm{~m}$ open pool fire.

\section{Temperature reduction ratio}

The temperature reduction ratio (TRR) is defined as ratio of the difference in steady state temperature of bare plate and plate coated with paint to that of the bare plate. TRR is obtained for various combinations of plate thickness and paint thickness.

$$
\text { Temperature Reduction Ratio }=\frac{T_{\text {bare }}-T_{\text {paint }}}{T_{\text {bare }}}
$$

This parameter gives a clear indication of the effect of the paint thickness on the plate temperatures. Higher the TRR, better is the performance of the paint.

The TRR values obtained for Stainless Steel 310 plates in $0.5 \mathrm{~m}$ and $0.7 \mathrm{~m}$ pool fire are presented in Table 1. TRR is observed to be in the range of 0.1-0.4. In general, TRR is found to be increasing as the dry film thickness increases. $3.5 \mathrm{~mm}$ dry film thickness appears to be the best among other thicknesses covered in this study. The temperature reduction ratio is different for different thickness of Stainless Steel 310 plate for $3.5 \mathrm{~mm}$ dry film thickness. This is
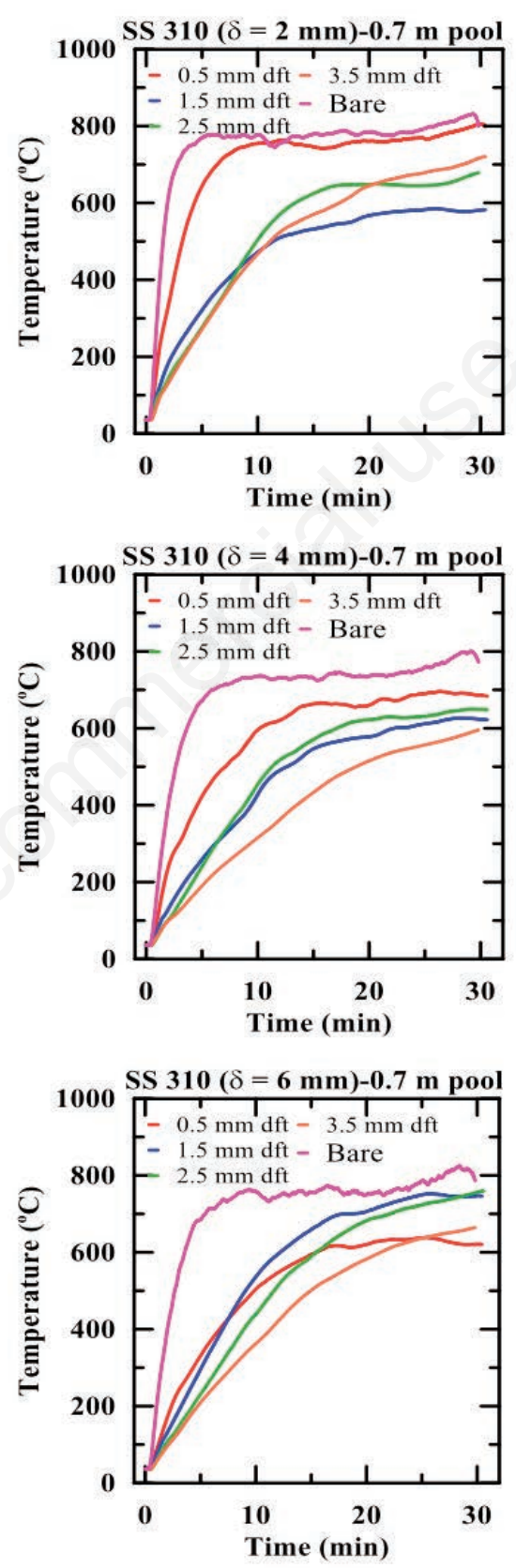

A because, the temperature of the coated plate decreases with the increase in the thickness of the plate. This observation is in line with the findings made in Appendix Figure 6A.

\section{Prediction of transient temperature distributions of stainless steel 310 plate painted with paint $B$}

The prediction of the transient temperature distribution is essential in real life applications. This involves the estimation of effective thermal conductivity of char using one dimensional heat transfer model sug-
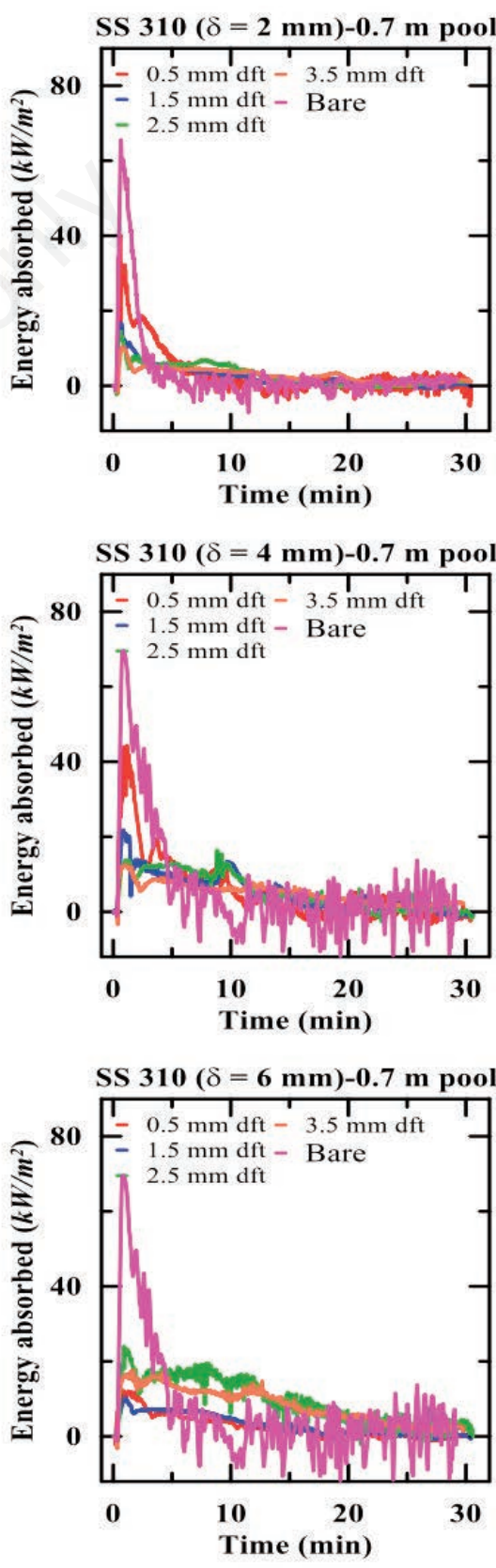

B

Figure 6. Temperature variation and energy absorption rate of the SS-310 plate with different dry film thickness in $0.7 \mathrm{~m}$ open diesel pool fire. SS310, stainless steel 310 
gested by Qiang et al. ${ }^{17}$

The governing heat equation for onedimensional heat transfer is given as:

$\alpha_{i} \frac{\partial^{2} T(x, t)}{\partial x^{2}}-\frac{\partial T(x, t)}{\partial t}=0$

where, $\alpha_{i}=\frac{k_{i}}{\rho_{i} c_{p i}}$ is the thermal diffusivity, $k_{i}$ is the thermal conductivity of the insulation and $\rho_{i} C_{p i}$ is the volumetric specific heat of the insulation.

At the steel and the insulation interface, the boundary condition is given by:

$-k_{i} \frac{\partial T(d f t, t)}{\partial x}=\frac{C_{s} \rho_{s}}{A_{i} / V} \frac{\partial T(d f t, t)}{\partial t}$

$T_{s}(t)=T(d f t, t)$

where $C_{s} \rho_{s}$ is the volumetric specific heat of the steel; $A_{i} / V$ is the section factor, in which $A_{i}$ is the appropriate area of the fire insulation material per unit length, and $V$ is the volume of the steel per unit length; and $d f t$ is the thickness of the insulation. Dirichlet boundaries boundary condition at the fireinsulation interface is given as:

$T(0, t)=T_{g}(t)$

$T_{\mathrm{g}}(t)$ and $T(0, t)$ are the fire temperature and the insulation temperature respectively, Qiang et al. ${ }^{17}$ demonstrated that Dirichlet boundary condition can be used and an equivalent thermal resistance can be calculated very easily and finally the thermal conductivity of the insulation.

Ignoring the heat absorbed by the insulation material, using the energy balance the steel temperature can be calculated by:

$$
\Delta T_{s}=\frac{T_{g}(t)-T_{s}(t)}{R_{e q}} \frac{1}{C_{s} \rho_{s}} \frac{A_{i}}{V} \Delta t
$$

$R_{e q}$ can be calculated after rearranging the above equation as:

$$
R_{e q}=\frac{T_{g}(t)-T_{s}(t)}{\Delta T_{s} / \Delta t} \frac{1}{C_{s} \rho_{s}} \frac{A_{i}}{V}
$$

Once the equivalent thermal resistance is known, the effective thermal conductivity can be easily calculated using the following relation:

$$
k_{e f f}=\frac{d f t}{R_{e q}}
$$

where $d f t$ is the initial dry film thickness of the intumescent paint applied on the substrate. The temperature at the fire and insulation interface is taken from Sudheer and Prabhu $^{18}$ at an $X / D$ of 0.12 and $Y / D$ of 0.18 0.22 for both the $0.5 \mathrm{~m}$ and $0.7 \mathrm{~m}$ open diesel pool fire as $777^{\circ} \mathrm{C}$ and $827^{\circ} \mathrm{C}$ respec- tively. Using Eq. 8, the thermal resistance is calculated and from the thermal resistance profile an average value is chosen to determine the constant thermal conductivity of the insulation. Appendix Figures 7 and 8 show the comparison between the temperatures calculated using the thermal conductivity (Eq. 9) and the experimental data for $0.5 \mathrm{~m}$ and $0.7 \mathrm{~m}$ open pool fire respectively. This comparison is shown only for a Stainless Steel 310 plate of $6 \mathrm{~mm}$ thickness. The deviation in the measured temperatures of the plate and the temperature of the plate predicted using effective thermal conductivity is not more than $15 \%$. The effective thermal conductivity is a function of paint thickness, substrate thickness and heat release rate (pool diameter).

Table 2 shows the thermal conductivity values for different Stainless Steel 310 plate for various dry film thicknesses of paint $B$ in $0.5 \mathrm{~m}$ and $0.7 \mathrm{~m}$ open pool fires. It reveals that the thermal conductivity value is directly proportional to the thickness of the plate.

\section{Conclusions}

An experimental investigation is conducted to study the transient temperature distribution of Stainless Steel 310 plate in cone calorimeter and open pool fire environment. The factors which influence the performance of the intumescent coating are investigated. The plate thicknesses considered in this study are $2 \mathrm{~mm}, 4 \mathrm{~mm}$ and 6 $\mathrm{mm}$. The dry film thicknesses used in this study are $0.5 \mathrm{~mm}, 1.5 \mathrm{~mm}, 2.5 \mathrm{~mm}$ and 3.5 $\mathrm{mm}$. The open pool fires were generated with a pool diameter of $0.5 \mathrm{~m}$ and $0.7 \mathrm{~m}$. Two paints are considered in the present study. Following conclusions may be drawn from this study: i) the fire environment poses more thermal severity on the bare Stainless Steel 310 plate compared to cone calorimeter even at higher heat flux of 75 $\mathrm{kW} / \mathrm{m}^{2}$. Hence, the inferences drawn from cone calorimeter may not be valid for open pool fire environment; ii) open pool fire experiments $(0.5 \mathrm{~m}$ diameter $)$ reveal that paint $\mathrm{B}$ (Nu-kem paint) is better than paint A (Goa Paints) due to its weak adhesive

Table 1. Temperature reduction ratio for a 0.5 and $0.7 \mathrm{~m}$ open pool diesel fire.

\begin{tabular}{|c|c|c|c|c|}
\hline Stainless steel 310 & $\begin{array}{l}\text { Open pool } \\
\text { fire }\end{array}$ & $\begin{array}{l}\text { Dry film } \\
\text { thickness }\end{array}$ & Therm & $\begin{array}{l}\text { ductivity } \\
(\cdot K)\end{array}$ \\
\hline$(\mathrm{mm})$ & & $(\mathrm{mm})$ & $0.5 \mathrm{~m} \mathrm{pool}$ & $0.7 \mathrm{~m} \mathrm{pool}$ \\
\hline 2 & 0.5 & 0.5 & 0.009 & 0.02 \\
\hline & & 1.5 & 0.02 & 0.01 \\
\hline & & 2.5 & 0.02 & 0.02 \\
\hline & & 3.5 & 0.02 & 0.03 \\
\hline 4 & 0.5 & 0.5 & 0.009 & 0.03 \\
\hline & & 1.5 & 0.04 & 0.02 \\
\hline & & 2.5 & 0.03 & 0.04 \\
\hline & & 3.5 & 0.03 & 0.05 \\
\hline 6 & 0.5 & 0.5 & 0.009 & 0.025 \\
\hline & & 1.5 & 0.05 & 0.06 \\
\hline & & 2.5 & 0.065 & 0.08 \\
\hline & & 3.5 & 0.04 & 0.07 \\
\hline
\end{tabular}

\begin{tabular}{lccc}
$\begin{array}{l}\text { Plate thickness } \\
\text { (Stainless steel 310) } \\
(\mathrm{mm})\end{array}$ & $\begin{array}{c}\text { Temperature reduction ratio } \\
(\mathrm{mm})\end{array}$ & $\mathbf{0 . 5} \mathrm{m}$ pool & $\mathbf{0 . 7} \mathrm{m}$ pool \\
2 & & & \\
& 0.5 & 0.19 & 0.03 \\
& 1.5 & 0.10 & 0.29 \\
& 2.5 & 0.20 & 0.18 \\
& 3.5 & 0.31 & 0.16 \\
4 & 0.5 & 0.23 & 0.16 \\
& 1.5 & 0.08 & 0.24 \\
& 2.5 & 0.32 & 0.21 \\
& 3.5 & 0.38 & 0.28 \\
\hline 6 & 0.5 & 0.23 & 0.23 \\
& 1.5 & 0.19 & 0.09 \\
& 2.5 & 0.27 & 0.08 \\
& 3.5 & 0.44 & 0.20 \\
\hline
\end{tabular}

Table 2. Effective thermal conductivity for paint $B$ in $0.5 \mathrm{~m}$ and $0.7 \mathrm{~m}$ open pool fire. 
property; iii) evaluation of paint B in $0.5 \mathrm{~m}$ and $0.7 \mathrm{~m}$ pool fire experiments suggests that a dry film thickness of $3.5 \mathrm{~mm}$ is better compared to other thicknesses $(0.5 \mathrm{~mm}, 1.5$ $\mathrm{mm}$ and $2.5 \mathrm{~mm}$ ) covered in this study; iv) estimated effective thermal conductivity of intumescent paint exposed to pool fire is suggested for a given pool fire diameter, dry film thickness and Stainless Steel 310 plate thickness. This thermal conductivity is able to predict the temperature variation of the plate within $15 \%$.

\section{References}

1. Vandersall HL. Intumescent coating systems, their development and chemistry. J Fire Flammabil 1971;2:97-140.

2. Rhys JA. Intumescent coatings and their uses. Fire Mat 1980;4:154-6.

3. Zhang J, Delichatsios MA, McKee M, Ukleja S. Experimental and numerical study of burning behaviors of flaxboard with intumescent coating and nanoparticles in the cone calorimeter and single burning item tests. Fire Mat 2011;36: 554-64.

4. Horrocks AR, Wang MY, Hall ME, et al. Flame retardant textile back-coatings. Part 2. Effectiveness of phosphorus-containing flame retardants in textile back-coating formulations. Polymer Int 2000;49:1079-91.

5. Duquesne S, Magnet S, Jamaa C, Delobel R. Intumescent paints: fire protective coatings for metallic substrates. Surface Coatings Technol 2004;1801:302-7.

6. Deogon M, Hall R, Socrates G. A sim- ple and theoretical model for intumescent paints. Constr Build Mat 1988;2: 92-5.

7. Jimenez M, Duquesne S, Bourbigot S. Intumescent fire protective coating: toward a better understanding of their mechanism of action. Thermochim Acta 2006;449:16-26

8. Gu J, Zhang G, Dong S, et al. Study on preparation and fire-retardant mechanism analysis of intumescent flameretardant coatings. Surface Coatings Technol 2007;201:7835-41.

9. Wang Z, Han E, Ke W. An investigation into fire protection and water resistance of intumescent nano-coatings. Surface Coatings Technol 2006;201:1528-35.

10. Bartholmai M, Schartel B. Assessing the performance of intumescent coatings using bench scaled cone calorimeter and finite difference simulations. Fire Mat 2007;31:187-205.

11. Han Z, Fina A, Malucelli G, Camino G. Testing fire protective properties of intumescent coatings by in-line temperature measurements on a cone calorimeter. Prog Organic Coatings 2010;69:475-80.

12. Zverev VG, Nesmelov VV, Tsimbalyuk AF. Modeling heat and mass transfer in intumescent fire-retardant coatings. Combustion Explosion Shock Waves 1998;34:198-205.

13. Rodier S, Autrique L, Perez L, et al. Fire protective coatings evaluation: tests and modeling based on a nonlinear partial differential equations system. Proceedings of the 17th IMACS World Congress, July 2005, France. 2005. Available from: https://www.research-
gate.net/publication/260362794_Fire_p rotective_coatings_evaluation_tests_an d_modeling_based_on_a_non_linear_p artial_differential_equations_system

14. Mesquita L, Piloto P, Pinto T. Numerical Estimation for Intumescent Thermal Protection using OneDimensional IHCP. ECCOMAS 2008: Proceedings of the 8th World Congress on Computational Mechanics, 2008 June 30-July 4, Venice, Italy. Barcelona: International Association for Computational Mechanics/European Community on Computational Methods in Applied Sciences 2008. Available from: https://www.tib.eu/en/search/ id/TIBKAT\%3A577226703/8th-WorldCongress-on-Computational-Mechanics-WCCM8/

15. Staggs JEJ. Thermal conductivity estimates of intumescent chars by direct numerical simulation. Fire Safety J 2010;45:228-37.

16. Staggs JEJ. Estimating the thermal conductivity of chars andporous residues using thermal resistor network. Fire Safety J 2002;37:107-19.

17. Li GQ, Lou GB, Zhang C, et al. Assess the fire resistance of intumescent coatings by equivalent constant thermal resistance. Fire Technol 2012;48:52946.

18. Sudheer S, Prabhu SV. Measurement of flame emissivity of hydrocarbon pool fires. Fire Technol 2012;48:183-217. 